\title{
Vida Saludable: Los alimentos pueden afectar sus medicamentos ${ }^{1}$
}

\author{
Paulina Wittkowsky y Linda B. Bobroff ${ }^{2}$
}

¿Puede ser que los alimentos que uno come afecten la forma en que los medicamentos actúan? Ésto es muy probable. Algunos alimentos pueden afectar la manera en que los medicamentos con prescripción o sin prescripción médica funcionan, ya sea retardando, disminuyendo o aumentando la cantidad del medicamento que el cuerpo absorbe. Esto puede ocasionar efectos secundarios peligrosos y no deseados. Tome en cuenta la siguiente información para reducir el riesgo de interacciones comunes entre alimentos y medicamentos.

\section{Bebidas Alcohólicas}

Ingerir bebidas alcohólicas mientras se toma ciertos medicamentos puede ser muy peligroso. Algunos medicamentos que pueden ser alterados por el consumo de alcohol son: el acetaminofén $\left(\right.$ Tylenol $\left.^{\mathrm{Ts}}\right)$, el antihistamínico $\left(\right.$ Benadryl $\left.^{\mathrm{Tm}}\right)$, y el ibuprofeno $\left(\right.$ Motrin $\left.^{\mathrm{Tm}}\right)$. No beba alcohol cuando tome estos medicamentos o sus derivados. Siempre lea la etiqueta del envase, y pregúntele a su farmacéutico si no está seguro de una posible reacción si va a consumir alcohol.

\section{Jugo de Toronja}

Aunque algunas medicamentos prescritos, como aquéllos que reducen la presión arterial o el colesterol, pueden interactuar con el jugo de toronja (pomelo o grapefruit), la mayoría no lo hace. Hable con su médico o farmacéutico si la posibilidad de una interacción le

1. Este documento, FCS8622-Span (the English version of this Spanish language leaflet is FCS8622, Healthy Living: Food Can Affect Your Medicines), es uno de una serie de publicaciones del Departamento de Ciencias de la Familia, la Juventud y la Comunidad, Servicio de Extensión Cooperativa de la Florida, Instituto de Alimentos y Ciencias Agrícolas, Universidad de la Florida (UF/IFAS Extension). Fecha de primera publicación: marzo 2004. Revisado enero 2018. Visite nuestro sitio web EDIS en <http://edis.ifas. ufl.edu>.

2. Paulina Wittkowsky, MS, RD, anterior asistente educativo; y Linda B. Bobroff, PhD, RDN, profesora, Departamento de Ciencias de la Familia, la Juventud y la Comunidad, Servicio de Extensión Cooperativa de la Florida, Instituto de Alimentos y Ciencias Agrícolas, Universidad de la Florida, Gainesville, FL 32611.

El uso de estas marcas en esta publicación es solamente con el propósito de proveer información específica. UF/IFAS no avala ni garantiza los productos mencionados y las referencias hechas a ellos en esta publicación, no significa que cuentan con nuestra aprobación o exclusión de otros productos de composición semejantes. 
preocupa. Si quiere seguir disfrutando del jugo de toronja es posible que su médico pueda recetarle otra medicina similar que no interactúe con el jugo y le ofrezca el mismo beneficio.

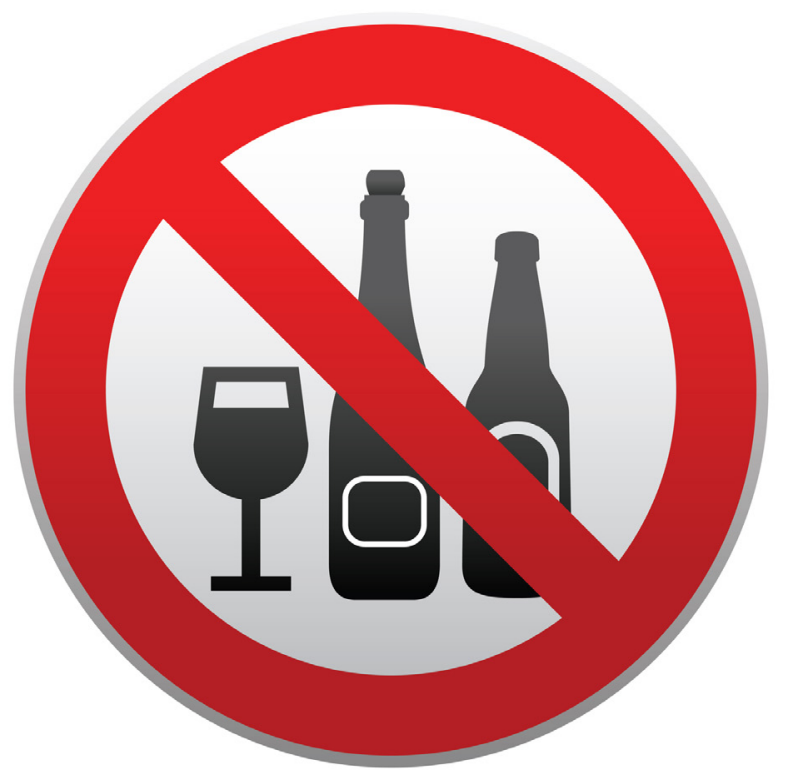

Figura 1. Asegúrese de preguntarle a su médico si puede beber alcohol mientras toma ciertos medicamentos.

Credits: chokkicx/gettyimages.com

\section{Leche}

Algunos antibióticos, como la tetraciclina y los floroquinolones (Levaquin), no se deberían tomar con leche $\mathrm{u}$ otros productos lácteos, suplementos de calcio o con anti-ácidos como Tums $^{\mathrm{TM}}$. El calcio en estos productos disminuye la habilidad del cuerpo para absorber los antibióticos.

\section{Verduras}

Las verduras que contienen vitamina $\mathrm{K}$, como la espinaca, col rizada y las coles de Bruselas, pueden reducir la eficacia de medicamentos anticoagulantes (como el Coumadin ${ }^{\mathrm{Tw}}$ ). Su médico o farmacéutico puede medir regularmente la eficacia de su medicamento durante sus visitas. Si usted mantiene un consumo diario de estas verduras, su médico puede recetar una dosis adecuada para su cuerpo.

\section{Tómelos con Alimentos}

Lea cuidadosamente todas las instrucciones en el envase. Ciertos medicamentos deben ser ingeridos con alimentos para prevenir la irritación del estómago. Ejemplos incluyen el ibuprofeno $\left(\right.$ Motrin $^{\mathrm{TM}}$ ) y ciertos esteroides (Medrol o Prednisone).

\section{Pregúntele a su doctor o farmacéutico si necesita más información sobre como los alimentos pueden afectar sus medicamentos.}

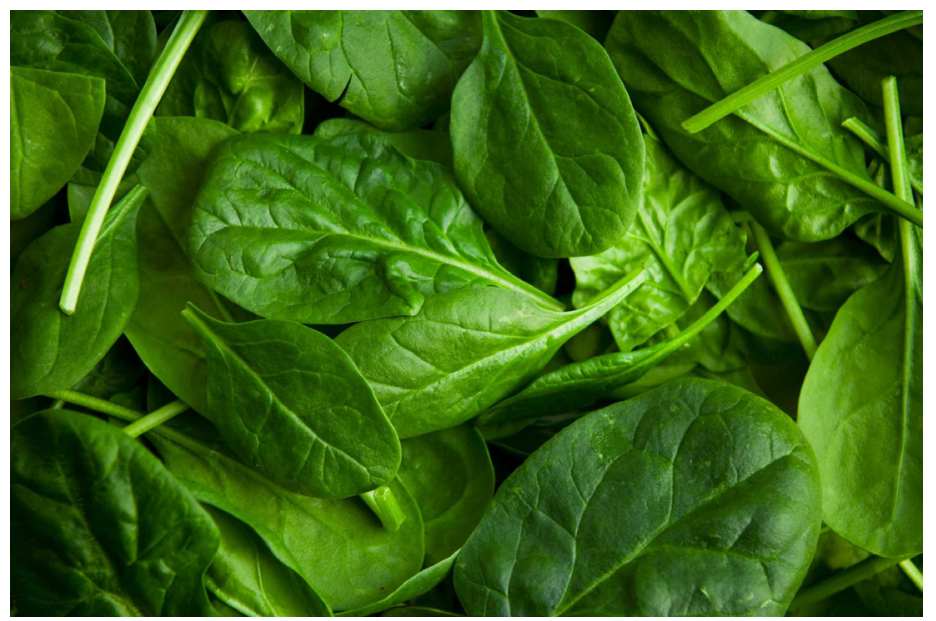

Figura 2. ¿Toma Ud. anticoagulantes? Si usted necesita esta medicina, su médico o farmacéutico tendrá que conocer su consumo diario de ciertas verduras de hojas verdes, como la espinaca.

Credits: Kativ/gettyimages.com 